\title{
Science gender gap probed
}

\section{Overt sexism is no longer the norm, but societal barriers remain for women in science.}

\section{BY GWYNETH DICKEY ZAKAIB}

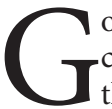
oodbye glass ceiling; so long old-boys club. The metaphor that best describes the challenge facing women in science today is the invisible web. Its multiple strands - some social, some biological, some institutional - can make it significantly harder for female researchers to achieve as much, as fast, as their male counterparts.

So concludes a study that set out to explore the persistent gap in the number of women in maths-intensive fields such as physics, computer science and engineering. It finds that overt discrimination of the sort that would make a female candidate less likely to be hired, published or funded when competing against an equally qualified male is largely a thing of the past. Instead, trade-offs between pursuing a career and raising a family, coupled with societal factors and gender expectations that can influence professional choices at a young age, are more likely to account for the shortage of women in some fields.

A 2008 survey of US universities by the National Science Foundation revealed that less than $30 \%$ of $\mathrm{PhDs}$ in the physical sciences were awarded to women. Higher up the ranks, women make up only about $10 \%$ of full professorships in physics-related disciplines. Yet when psychologists Stephen Ceci and Wendy Williams of Cornell University in Ithaca, New York, sifted through 20 years of research, they found little evidence of continued gender bias in journal reviewers, granting agencies or hiring committees. Their analysis, published on 7 February (S. J. Ceci and W. M. Williams Proc. Natl Acad. Sci. USA doi:10.1073/pnas.1014871108; 2011), contrasts with reports that suggest overt discrimination remains a significant problem.

"There are constant and unsupportable allegations that women suffer discrimination in

these arenas, and we show conclusively that women do not," says Williams.

Ceci and Williams conclude that female researchers lag behind their male counterparts in professional advancement because of a broader set of societal realities. Much of the problem, they say, can be boiled down to external factors related to family formation and child rearing. Motherhood can make women less likely to choose research careers than male scientists of equal ability, or lead them to

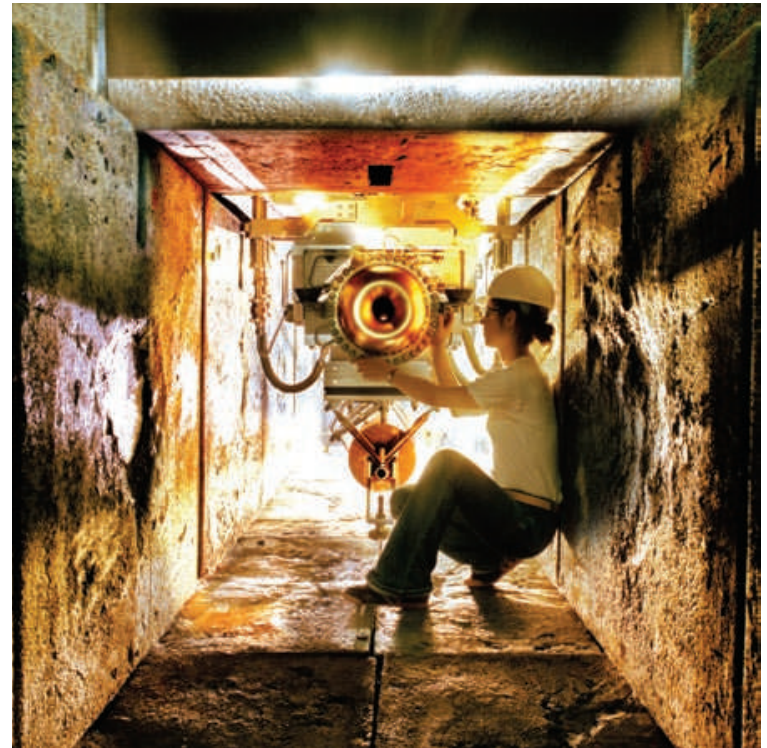

Too rare a sight: working on a neutrino experiment at Fermilab. choose academic positions with larger teaching loads but more regular hours, sacrificing time for research. The authors also point out that the strict tenure timeline conflicts directly with women's window for child rearing.

"A woman who has young children is still expected to come up for tenure 5-6 years after she starts her job," says Williams. "It creates a virtually insurmountable obstacle."

Such constraints affect women across all academic disciplines, Ceci and Williams point out, so additional factors must account for why the gender gap in science is greatest in mathsintensive fields. This could include a difference in the fields women prefer, a choice that can be socially influenced, regardless of aptitude.

"They are probably right that overt discrimination has declined, but it's naive to suggest that judging applicants differently based on their gender is a thing of the past," says Christianne Corbett, a senior researcher at the American Association of University Women (AAUW), based in Washington DC. In their study, Ceci and Williams criticize an AAUW report published las year that claims there is discrimination in peer review and "a systematic underrating of female applicants" in hiring.

Ceci and Williams say that a continuing focus on discrimination could be drawing attention away from the true causes of the disparity. They suggest, for example, that gender-sensitivity training for review and hiring committees may no longer be needed, and argue that efforts should be redirected to promoting flexible tenure policies for women with young children. Educational programmes could also help female graduate students to make more informed decisions about family and career.

Nancy Hopkins, a molecular biologist who chaired a landmark study of gender inequality in faculty members at the Massachusetts Institute of Technology (MIT) in Cambridge, cautions that progress in gender equality could backslide if successful practices are abandoned.

She observes that some family-friendly changes are already being made at MIT, such as the availability of on-campus day care for faculty members with young children. "We're about two-thirds of the way home," Hopkins says, but she notes that many institutions have further to go.

\section{LATEST NEWS \\ ESA mission selection has consequences for international collaborations go.nature.com/ ilu2m9 \\ MORE NEWS \\ - Are antipsychotics shrinking patients' brains? go.nature.com/hteezz - Outdoor mosquitoes could defy control go.nature.com $/ 7 \mathrm{kzztq}$ \\ - Fly brain structure illuminated go.nature.com/ubwbuj \\ - Solar-sail success go.nature.com/ybapod}

\section{ON THE BLOG}

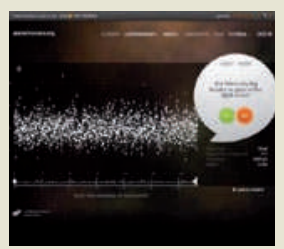

Citizen scientists beat Kepler team to likely planets go nature. com/1zgra9 